\title{
Relation of armspan to height and the prediction of lung function
}

\author{
MARIENNE E HIBBERT, ANNA LANIGAN, JOAN RAVEN, PETER D PHELAN \\ From the Department of Thoracic Medicine, Royal Children's Hospital, and the University of Melbourne \\ Department of Paediatrics, Melbourne, Australia
}

ABSTRACT Height and armspan were measured in healthy 8-18 year old boys and girls to assess the appropriate correction factor to be applied when height cannot be measured easily. No correction factor was found necessary, height being directly estimated from armspan.

Predicted lung function is usually based on height. In scoliosis, muscular dystrophy, paraplegia, and any condition where height is difficult to measure armspan is often substituted for height, and a correction factor applied. ${ }^{12}$ Previous measurements of height and armspan in children and adolescents have been based on small numbers, ${ }^{12}$ and so there is some doubt about the validity of these correction factors.

As part of a large longitudinal study of lung growth in healthy children and adolescents, height and armspan were measured annually. These data were examined to see whether armspan differed from height and, if so, to determine the appropriate correction factor.

\section{Methods}

Two groups of healthy children were enrolled in 1979, 124 boys and 128 girls aged 8 years and 120 boys and 140 girls aged 12 years. They were studied annually on six and seven occasions respectively. Not all the children were available every year, there being 1175 measurements on the girls and 1193 on the boys. Those below the 3rd centile or above the 97th centile for height or weight at their first visit were excluded, as were those with any skeletal deformity, respiratory disease, or cardiac disease.

Height was measured without shoes, with the child's back to the ruler and neck extended. ${ }^{3}$ Armspan was measured as the distance between the tips of the middle fingers while the arms were stretched horizontally with the back to the ruler. Measurement was to the closest $0.1 \mathrm{~cm}$, although the error of both height and span was $\pm 0.5 \mathrm{~cm}$.

The data were treated as if each time point represented a separate individual as the non-independence of the time

Address for reprint requests: Dr M E Hibbert, Department of Thoracic Medicine, Royal Children's Hospital, Parkville, Victoria 3052, Australia.

Accepted 8 January 1988 points in such individuals gives minimal bias in such a healthy sample.

The data were plotted and multiple linear stepwise regression was performed. ${ }^{4}$ The normality of the data and the residuals were examined.

\section{Results}

Height and armspan were highly correlated for both girls $(R=0.97)$ and boys $(R=0.98)$ and the regression equations were:

\section{Female}

$$
\begin{gathered}
\text { Height }=0.915 \text { armspan }+0.131 \\
R^{2}=0.94 \\
S E=0.032 \\
n=1175
\end{gathered}
$$

Male

$$
\begin{gathered}
\text { Height }=0.911 \text { armspan }+0.132 \\
\mathrm{R}^{2}=0.97 \\
\mathrm{SE}=0.031 \\
\mathrm{n}=1193
\end{gathered}
$$

Multiple linear stepwise regression showed that age explained only a further $0.6 \%$ of the variance in height in girls and $0.3 \%$ of the variance in the boys. Although statistically significant it is not of practical importance.

The data, plotted with the regression line and $95 \%$ confidence interval for prediction in figures 1 (girls) and 2 (boys), display the close association of height and armspan. The scatter is greater in the girls than the boys but as the sample is so large the standard error of the estimate is quite low, and almost the same for the two groups. The $13 \mathrm{~cm}$ intercept probably reflects the effect of age; the equation should not, however, be extrapolated beyond the age range (8-18 years) on which it is based. The mean armspan:height ratios were close to unity: 0.999 (SD 0.023) for girls and 1.006 $(0.022)$ for boys. The ratios do, however, change slightly from age 8 to 18 years (fig 3 ), confirming a small effect of age.

\section{Discussion}

The measurement of armspan and the subsequent application of a correction factor to estimate height has long been a practice in conditions where height is difficult to measure. There will also, however, be conditions where armspan as well as height will be difficult to obtain.

Linderholm and Lindren ${ }^{2}$ found a higher correlation of the armspan : height ratio with age, perhaps because of the wide 
70

.40 .

1.30.

1.20

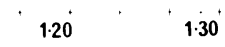

1.30

\section{Armspan (m)}



Fig 1 Plot of armspan versif height in girls with the regression equation and the $95 \%$ confidence interval for prediction.

Fig 2 Plot of armspan versus height in boys with the regression equation and the $95 \%$ confidence interval for prediction. 
Armspan:

height ratio



Fig 3 Plot of the mean armspan : height ratio (with 1 SD) for each age, $\star---\star$ boys; $\bigcirc-\bigcirc$ girls.

age range and small numbers in their sample and the tendency of older people to compress their spine. They also found the armspan : height ratios differed between the sexes (1.029 for males and 1.012 for females). Johnson and Westgate, 'who studied 139 subjects aged 6-30 years, found armspan to be greater than height and recommended that the adjustment factor of 1.03 should be applied for both sexes to estimate height from armspan.

In our healthy group of normal children the armspan is so close to height that adjustment is not necessary, and this did not change greatly with age. If we applied the correction factor of Johnson and Westgate height would be under- estimated by $3 \%$, and with that of Linderholm and Lindgren height would be underestimated by $2.9 \%$ in boys and $1.2 \%$ in girls. A lower predicted value would then be calculated for lung function and this may lead to an underestimation of abnormality. For example, a boy of armspan $150 \mathrm{~cm}$ would have a corrected height of $1.56 \mathrm{~m}$ with the correction factor of 1.03. Predicted vital capacity ${ }^{5}$ would then be underestimated by $260 \mathrm{ml}$ or $9.7 \%$, which is more than double the $3.5 \%$ coefficient of variation for intrasubject variability. ${ }^{6}$ The armspan : height ratios of this study have the greatest deviation from unity at the age of 16 for boys. If no correction is made at this age an overestimation of $3.3 \%$ will result, which is less than the intrasubject variability of the test.

In conclusion, there is a slight trend in the armspan : height ratio with age but it is so small that correction factors need not be applied to armspan for estimating height. Height can be directly estimated by measuring armspan.

\section{References}

1 Johnson BE, Westgate HD. Methods of predicting vital capacity in patients with scoliosis. J Bone Joint Surg 1970;52-A:1433-9.

2 Linderholm $\mathrm{H}$, Lindgren $\mathrm{U}$. Prediction of spirometric values in patients with scoliosis. Acta Orthop Scand 1978;49:469-74.

3 Tanner JM. Fetus into man. Cambridge, Mass: Harvard University Press, 1978.

4 Anonymous. SPSSX users guide. New York: McGraw-Hill, 1983.

5 Cook CD, Hamann JF. Relation of lung volumes to height in healthy persons between ages 5 and 38 years. J Pediatr 1961;59:710-4.

6 Hutchinson AA, Erben A, McLennan L, Landau LI, Phelan P. Intrasubject variability of pulmonary function testing in healthy children. Thorax 1981;36:370-7. 